\title{
BMJ Open Micronutrient deficiencies and developmental delays among infants: evidence from a cross-sectional survey in rural China
}

\author{
Renfu Luo, ${ }^{1}$ Yaojiang Shi, ${ }^{2}$ Huan Zhou, ${ }^{3}$ Ai Yue, ${ }^{2}$ Linxiu Zhang, ${ }^{1}$ Sean Sylvia, ${ }^{4}$ \\ Alexis Medina, ${ }^{5}$ Scott Rozelle ${ }^{5}$
}

To cite: Luo R, Shi Y, Zhou $\mathrm{H}$, et al. Micronutrient deficiencies and developmental delays among infants: evidence from a cross-sectional survey in rural China. BMJ Open 2015;5:e008400. doi:10.1136/bmjopen-2015008400

- Prepublication history and additional material is available. To view please visit the journal (http://dx.doi.org/ 10.1136/bmjopen-2015008400).

Received 3 April 2015 Revised 30 July 2015 Accepted 14 September 2015

CrossMark

For numbered affiliations see end of article.

Correspondence to Dr Huan Zhou; kathy0228@163.com

\section{ABSTRACT}

Objectives: Research increasingly indicates the importance of the nutritional programming that occurs in the first 2-3 years of life. Quality nutrition during this brief window has been shown to have large and significant effects on health and development throughout childhood and even into adulthood. Despite the widespread understanding of this critical window, and the long-term consequences of leaving nutritional deficiencies unaddressed, little is known about the status of infant nutrition in rural China, or about the relationship between infant nutrition and cognitive development in rural China.

Design, setting and participants: In April 2013 and October 2013, we conducted a survey of 1808 infants aged 6-12 months living in 351 villages across 174 townships in nationally designated poverty counties in rural areas of southern Shaanxi Province, China.

Main outcome measures: Infants were administered a finger prick blood test for haemoglobin and assessed according to the Bayley Scales of Infant Development. They were also measured for length and weight. Caregivers were administered a survey of demographic characteristics and feeding practices.

Results: We found that $48.8 \%$ of sample infants were anaemic, $3.7 \%$ were stunted, $1.2 \%$ were underweight and $1.6 \%$ were wasted. Approximately $20.0 \%$ of the sample infants were significantly delayed in their cognitive development, while just over $32.3 \%$ of the sample infants were significantly delayed in their psychomotor development. After controlling for potential confounders, infants with lower haemoglobin counts were significantly more likely to be delayed in both their cognitive $(p<0.01)$ and psychomotor development $(p<0.01)$.

Conclusions: The anaemia rates that we identify in this study classify anaemia as a 'severe' public health problem according to the WHO. In contrast, there is virtually no linear growth failure among this population. We find that low haemoglobin levels among our sample population are associated with significant cognitive and psychomotor delays that could eventually affect children's schooling performance and labour force outcomes.

Trial registration number: ISRCTN44149146.

\section{Strengths and limitations of this study}

- The key strengths of this study are its population-based sampling technique, large sample size (over 1800 children) and rigorous child development testing, all of which increase confidence in the validity and generalisability of our findings.

- The primary study limitation is that we were unable to conduct full blood panel testing for nutritional deficiencies, and are therefore limited to considering haemoglobin as our sole indicator of micronutrient deficiency. We acknowledge that (1) low haemoglobin levels alone do not definitively indicate iron deficiency and (2) other micronutrient deficiencies such as zinc, folate or vitamin A may be driving our correlational results.

- Since our study is correlational in nature, we are limited in the conclusions we may draw from our results. Future work is needed to refine the results presented here, and to better identify whether a causal link exists between infant nutrition and early child development in rural China.

\section{INTRODUCTION}

Despite China's rapid growth, many residents in inland provinces are still plagued by poverty. One of the outcomes of this poverty is that up to $40 \%$ of primary school children in poor regions suffer from micronutrient deficiencies. $^{1}$ In China, the most common form of micronutrient deficiency among school-aged children is iron deficiency. ${ }^{2}$ Iron deficiency anaemia in the first years of life has been related to many adverse consequences. In the short term, infants with iron deficiency anaemia are at higher risk of cognitive, social and emotional delays. ${ }^{3-11}$ In the longer run, it can negatively affect school performance and behaviour, reduce overall educational attainment and negatively affect work outcomes into adulthood; these 
consequences are irreversible even if the anaemia is corrected in later childhood. ${ }^{12-15}$ Many of these consequences can be avoided, however, simply through proper dietary intake in the first years of life; studies have shown that regular iron supplementation can reduce anaemia rates by as much as $50 \% .{ }^{16}$ Previous work in China has shown that interventions of vitamin supplements and school lunch programmes reduce anaemia prevalence and raise test scores among primary school children. ${ }^{17-19}$

Little is known, however, about micronutrient deficiencies among one of the most vulnerable population groups in China. Research increasingly indicates the importance of the nutritional programming that occurs in the first 2-3 years of life. ${ }^{20-22}$ Quality nutrition during this brief window has been shown to have large and significant effects on health and development throughout childhood, and even to affect outcomes in adulthood. ${ }^{12-14}$

Despite the widespread understanding of this critical window and the long-term consequences of leaving nutritional deficiencies unaddressed, little is known about the status of infant nutrition or the relationship between infant nutrition and cognitive development in rural China. Although researchers have attempted to measure the prevalence of nutritional deficiencies in China overall, evidence on the situation in rural China is mixed. The Chinese Food and Nutrition Surveillance System found anaemia prevalence among infants aged $6-12$ months in rural areas to be around $28 \%$ in $2010 .^{2}$ Other, more geographically focused studies have found anaemia prevalence ranging from $22.6 \%$ (in Guangxi) ${ }^{23}$ to $58.2 \%$ (in Gansu) ${ }^{24}$ among the same age group. Moreover, most of these studies have been based on relatively small sample sizes, limited sample areas or both. To the best of our knowledge, while there has been one study on the impact of mothers' nutrition on early infant development in China, ${ }^{25}$ no studies have reported on the status of infant development or examined the correlation between infant micronutrient deficiencies and development among infants aged 6-12 months in China.

The goal of this paper is to provide an overview of infant nutrition in rural China, and to explore the link between nutritional status and child development. More specifically, we measure the prevalence of micronutrient deficiencies (haemoglobin ( $\mathrm{Hb})$ concentrations/ anaemia) and macronutrient deficiencies (stunting, underweight and wasting) among infants aged 6-12 months living in nationally designated poverty counties in rural Shaanxi Province. In addition, we examine correlations between $\mathrm{Hb}$ concentrations, and infants' cognitive and motor development, using the Bayley Scales of Infant Development (BSID).

\section{METHOD}

Sample selection

Our study was conducted in 2013, in 11 nationally designated poverty counties located in southern Shaanxi Province. From each of these 11 counties, all townships (the middle level of administration between county and village) were selected to participate in the study. There were two exceptions to this rule: we excluded the one township in each county that housed the county seat, and we excluded any townships that did not have any villages with a population of 800 or more.

Our study was conducted in two waves: one in April 2013, and another 6 months later, in October 2013. Sample villages were selected at the time of our first visit in April 2013, and revisited in October 2013. At the time of each visit to the sample villages, we sampled all infants in our desired age range (6-12 months) living in the village.

The sample villages were selected in April 2013, as follows. To meet the power requirements of a larger, interventional study (not reported in this paper), we required a minimum of five infants in each township. (For more details on the exact specifications of our power calculations, please see the online supplementary appendix). With this requirement in mind, we first randomly selected one village (with a population of 800 or more) from each township to participate. A list of all registered births over the past 12 months was obtained from the local family planning official in each village. All infants in our desired age range (6-12 months) were enrolled in the study. If a village had fewer than five infants in our desired age range, we randomly selected an additional village in the same township for inclusion in the study, and continued to randomly select additional villages until five infants per township had been found.

The sample villages were all revisited in October 2013, and a new cohort of infants (also aged 6-12 months) was surveyed at that time. Subsequently, overall, our study included 1808 infants in 351 villages across 174 townships.

All surveys and tests of nutritional status and cognitive development were administered on the same day for each household.

\section{Data collection}

With the assistance of trained nurses from Xi'an Jiaotong Medical School, we collected $\mathrm{Hb}$ concentrations from all participating infants and their mothers. $\mathrm{Hb}$ concentrations were measured onsite using a HemoCue $\mathrm{Hb} 201+$ finger prick system. The nurses also measured the length and weight of each infant, according to WHO recommendations. ${ }^{26}$

Teams of trained enumerators collected socioeconomic data from all households participating in the study. Each infant's primary caregiver was identified, and administered a detailed survey on parental and household characteristics, including each child's gender and birth order, maternal age and education, and whether the family was receiving minimum living standard guarantee payments (a poverty indicator). The infant's age was obtained from his or her birth certificate. The primary caregiver was individually identified by each family as the individual most responsible for the infant's care (typically the child's mother or grandmother). 
All infants were also administered the BSID Version I, an internationally scaled test of infant and toddler cognitive and motor development. ${ }^{27}$ This test is well recognised in the psychological literature and is listed by the American Psychiatric Association as a way to diagnose certain developmental disorders. ${ }^{28}$ The test was formally adapted to the Chinese language and environment in 1992, and scaled according to an urban Chinese sample. ${ }^{29}{ }^{30}$ Following the example of other published studies that use the BSID to assess infant development in China, ${ }^{25} 3132$ it was this officially adapted version of the test that was used in this study. The test has an inter-rater reliability of 0.99 for each of the two subindices, the Mental Development Index (MDI) and the Psychomotor Development Index (PDI). ${ }^{33}$ (Both indices are described in more detail below.) The test-retest reliability is high, at 0.82 for MDI and 0.88 for PDI. ${ }^{33}$ The parallel forms reliability is also high, at 0.85 for MDI and 0.87 for PDI, indicating that the test scores are consistent when there is a variation in the methods or instruments used in the test. ${ }^{33}$ All BSID enumerators attended a week long training course on how to administer the BSID, including a 2.5 day experiential learning programme in the field. The test was administered one-on-one in the household using a set of standardised toys and a detailed scoring sheet. The BSID takes into consideration each infant's age in days, as well as whether he or she was a premature birth. These two factors, combined with the infant's performance on a series of tasks using the standardised toy kit, contribute to the establishment of two independent, internationally standardised scores: MDI, which evaluates memory, habitation, problem solving, early number concepts, generalisation, classification, vocalisations and language to produce a measure of cognitive development; and PDI, which evaluates gross muscle groups (rolling, crawling and creeping, sitting, standing, walking, running and jumping) and fine motor manipulation to produce a measure of psychomotor development. ${ }^{34}$ This study represents one of the largest administrations of the BSID ever conducted in China and, to the best of our knowledge, the only administration of the BSID ever conducted in rural communities in China's nationally designated poverty counties.

\section{Ethical approval}

All participating caregivers gave their oral consent for both their own and their infant's involvement in the study. Children who were found to have severe anaemia were referred to the local hospital for treatment.

\section{Statistical analysis}

Anaemia status was assessed based on finger blood analysis for $\mathrm{Hb}$. Following internationally accepted standards, anaemia was defined as $\mathrm{Hb}<110 \mathrm{~g} / \mathrm{L}$, moderate anaemia was defined as $\mathrm{Hb}>70 \mathrm{~g} / \mathrm{L}$ but $<100 \mathrm{~g} / \mathrm{L}$, and severe anaemia was defined as $\mathrm{Hb}<70 \mathrm{~g} / \mathrm{L} .{ }^{35} 36$
Physical indicators of length and weight were compared with the 2006 WHO child growth standards, to calculate length-for-age (LAZ), weight-for-age (WAZ) and weight-for-length z-scores (WLZ). ${ }^{37}$ We followed internationally recognised cut-offs to consider children whose LAZ, WAZ, or WLZ fall more than two SDs below the international mean to be stunted, underweight or wasted, respectively. ${ }^{38}$

Cognitive development (MDI) and psychomotor development (PDI) scores were determined using the BSID protocol. Both indices are scaled to have an expected mean of 100 and a SD of 16. Scores on each index can range between 50 and $150 .{ }^{33}$ Mild impairment for each index is defined as $70 \leq \mathrm{MDI}<80$ and $70 \leq \mathrm{PDI}<80$, while moderate or severe impairment for each index is defined as $\mathrm{MDI}<70$ and $\mathrm{PDI}<70 .{ }^{33}$ Infants failing to achieve the minimum MDI or PDI score (50) were assigned a score of $49 .{ }^{39}$

Statistical analyses were performed using STATA 12.0. p Values below 0.05 were considered statistically significant. Linear regression and logistic regression were used for multivariate analyses as appropriate. We included the following variables as potential confounders in the multivariate analysis: gender, age, whether the child was born prematurely, birth order, whether the child's mother was identified as the primary caregiver, maternal educational level and age, and whether the child's family received minimum living standard guarantee payments. All multiple linear regressions adjust for county fixed effects. SEs account for clustering at the village level. Lowess curves reflecting the relationship between $\mathrm{Hb}$ concentration and BSID score were estimated using the loess procedure in SAS.

\section{Role of the funding source}

The study sponsors had no role in study design; in the collection, analysis, or interpretation of data; in the writing of the report; or in the decision to submit the paper for publication.

\section{RESULTS}

Table 1 shows the demographic characteristics of the sample. Slightly over half of the sample infants were male $(53.2 \%)$. Around $4.6 \%$ of sample infants were premature and $62.6 \%$ were first-order births. The mother was the primary caregiver for $79.6 \%$ of the infants in the sample. The majority of the mothers $(81.1 \%)$ had completed fewer than 9 years of schooling; $49.9 \%$ were aged over 25 years. About a one-quarter (24.3\%) of sample families reported receiving minimum living standard guarantee payments, a form of government welfare for the lowest income families nationwide.

\section{$\mathrm{Hb}$ concentration, anaemia and physical development among rural Chinese infants}

$\mathrm{Hb}$ concentrations were normally distributed with a mean of $109.1 \mathrm{~g} / \mathrm{L}$ (table 2). In our sample, $48.8 \%$ of 
Table 1 Basic characteristics of sample infants in rural Shaanxi Province $(n=1808)$

\begin{tabular}{|c|c|c|}
\hline Characteristics & Frequency $(n)$ & Percentage \\
\hline \multicolumn{3}{|l|}{ Gender } \\
\hline Male & 961 & 53.2 \\
\hline Female & 847 & 46.8 \\
\hline \multicolumn{3}{|l|}{ Infant age (months) } \\
\hline 6 & 184 & 10.2 \\
\hline 7 & 301 & 16.6 \\
\hline 8 & 280 & 15.5 \\
\hline 9 & 276 & 15.3 \\
\hline 10 & 301 & 16.6 \\
\hline 11 & 466 & 25.8 \\
\hline \multicolumn{3}{|c|}{ Is the infant premature? } \\
\hline No & 1724 & 95.4 \\
\hline Yes & 84 & 4.6 \\
\hline \multicolumn{3}{|l|}{ Birth order of infant } \\
\hline First & 1132 & 62.6 \\
\hline Second or higher & 676 & 37.4 \\
\hline \multicolumn{3}{|c|}{ Mother is primary caregiver } \\
\hline No & 368 & 20.4 \\
\hline Yes & 1440 & 79.6 \\
\hline \multicolumn{3}{|c|}{ Maternal educational level (years) } \\
\hline$\leq 9$ & 1467 & 81.1 \\
\hline$>9$ & 341 & 18.9 \\
\hline \multicolumn{3}{|l|}{ Maternal age } \\
\hline Age $\leq 25$ & 906 & 50.1 \\
\hline Age $>25$ & 902 & 49.9 \\
\hline \multicolumn{3}{|c|}{ Family receives minimum living standard guarantee } \\
\hline No & 1369 & 75.7 \\
\hline Yes & 439 & 24.3 \\
\hline
\end{tabular}

infants had $\mathrm{Hb}$ concentrations below $110 \mathrm{~g} / \mathrm{L}$, indicating anaemia. A total of 363 infants (19.4\%) had Hb concentrations below $100 \mathrm{~g} / \mathrm{L}$, classifying them as moderately or severely anaemic. There was considerable variation in anaemia prevalence across the sample counties, ranging from $33.3 \%$ to $69.7 \%$.

Table 2 further shows indicators of the infants' physical development, as measured by LAZ, WAZ and WLZ. The data show that $3.7 \%$ of infants in our sample are stunted, $1.2 \%$ are underweight and $1.6 \%$ are wasted.
MDI and PDI among rural Chinese infants

BSID measures were available for all 1808 infants. Two per cent of the sample infants failed to achieve the minimum score (50) on the MDI and were assigned a score of 49. No infants scored below 50 on the PDI. Table 3 shows the MDI scores for all 1808 sample infants. The mean MDI score for the sample was 96.7, significantly lower than the expected mean of 100 $(p<0.001)$. The SD was 17.0. The BSID test results show that $6.9 \%$ had an MDI score below 70, thereby classifying them as moderately or severely impaired in their cognitive development. Around $13.1 \%$ of infants had an MDI score between 70 and 80, which indicates mild cognitive impairment. In total, $20.0 \%$ had MDI scores lower than 80

Table 3 also shows the PDI score for all 1808 sample infants. The mean PDI score for the sample was 90.0, significantly lower than both the observed MDI score and the expected mean PDI score of $100 \quad(p<0.001)$. The SD was 17.2. The data show that $13.1 \%$ of sample infants were moderately or severely impaired in their psychomotor development $(\mathrm{PDI}<70)$ and $19.2 \%$ were mildly impaired $(70 \leq \mathrm{PDI}<80)$.

\section{Multivariate analysis}

The multivariate analyses show a significant positive association between $\mathrm{Hb}$ concentrations and both MDI and PDI scores after controlling for potential confounding variables (table 4 ). More precisely, our analysis shows that a $10 \mathrm{~g} / \mathrm{L}$ rise in infant $\mathrm{Hb}$ concentration is associated with a 0.9 point rise in the MDI score and a 1.0 point rise in the PDI score. Logistic analyses using three commonly used BSID score cut-offs are largely consistent with this result for both MDI and PDI (see online supplementary appendix table $\mathrm{S} 1$ ).

Figure 1 shows a lowess plot of the relationship between $\mathrm{Hb}$ concentrations and BSID scores. Both panels show a positive relationship between $\mathrm{Hb}$ concentrations, and MDI and PDI scores. This positive relationship is approximately linear and evident both below and above the WHO cut-off for anaemia $(110 \mathrm{~g} / \mathrm{L})$.

\begin{tabular}{|c|c|c|}
\hline & Mean/per cent & $\mathrm{Cl}(95 \%)$ \\
\hline $\mathrm{Hb}$ concentration, g/L & $109.1 \pm 12.7$ & (108.5 to 109.7 ) \\
\hline \multicolumn{3}{|l|}{ Anaemia status } \\
\hline Total per cent anaemic $(\mathrm{Hb}<110 \mathrm{~g} / \mathrm{L})$ & $48.8(882)$ & (46.5 to 51.1$)$ \\
\hline Severe anaemia $(\mathrm{Hb}<70 \mathrm{~g} / \mathrm{L})$ & $0.7(12)$ & (0.3 to 1.0$)$ \\
\hline Moderate anaemia $(70 \mathrm{~g} / \mathrm{L} \leq \mathrm{Hb}<100 \mathrm{~g} / \mathrm{L})$ & $19.4(351)$ & (17.6 to 21.2$)$ \\
\hline Mild anaemia (100 g/L $\leq \mathrm{Hb}<110 \mathrm{~g} / \mathrm{L})$ & $28.7(519)$ & (26.6 to 30.8 ) \\
\hline Stunting $(L A Z<-2)$ & $3.7(68)$ & (2.9 to 4.6 ) \\
\hline Underweight (WAZ<-2) & $1.2(22)$ & (0.7 to 1.7$)$ \\
\hline Wasting (WLZ<-2) & $1.6(30)$ & (1.1 to 2.2$)$ \\
\hline
\end{tabular}

Data are presented as mean \pm SD or $\%(n)$ for categorical variables.

$\mathrm{Hb}$, haemoglobin; LAZ, length-for-age; WAZ, weight-for-age; WLZ, eight-for-length z-scores. 
Table 3 Cognitive and psychomotor development of sample infants in rural Shaanxi Province $(n=1808)$

\begin{tabular}{|c|c|c|}
\hline & $\begin{array}{l}\text { Mean/per } \\
\text { cent }\end{array}$ & Cl (95\%) \\
\hline MDI score & $96.7 \pm 17.0$ & (96.0 to 97.5 ) \\
\hline \multicolumn{3}{|l|}{ Cognitive impairment } \\
\hline Moderate or severe $(\mathrm{MDI}<70)$ & $6.9(125)$ & (5.7 to 8.1$)$ \\
\hline Mild $(70 \leq \mathrm{MDI}<80)$ & $13.1(237)$ & (11.6 to 14.7 ) \\
\hline Any $(\mathrm{MDI}<80)$ & $20.0(362)$ & (18.2 to 21.9$)$ \\
\hline PDI score & $90.0 \pm 17.2$ & (89.2 to 90.8$)$ \\
\hline \multicolumn{3}{|l|}{ Psychomotor impairment } \\
\hline Moderate or severe $(\mathrm{PDI}<70)$ & $13.1(236)$ & (11.5 to 14.6$)$ \\
\hline Mild $(70 \leq \mathrm{PDI}<80)$ & $19.2(348)$ & (17.4 to 21.1 ) \\
\hline Any $(\mathrm{PDI}<80)$ & $32.3(584)$ & (30.1 to 34.5 ) \\
\hline
\end{tabular}

\section{DISCUSSION}

We observed that $48.8 \%$ of infants aged 6-12 months in low-income areas of rural China are anaemic. This is nearly twice as high as the 2011 average for East and Southeast Asia. ${ }^{40}$ Nearly $20 \%$ of the sample suffers from moderate or severe anaemia. Stunting, underweight and wasting, however, are much less prevalent in this population, ranging from only $1.2-3.7 \%$. Such low rates are indicative of a population with virtually no linear growth failure, a notable finding for China, especially given that, as recently as 2012, stunting prevalence among children under 5 years of age in rural areas was observed to be around $20 \%{ }^{2}$ This contrast suggests that it is now the quality of infant diets, rather than the quantity of food, that is lacking in rural China today.
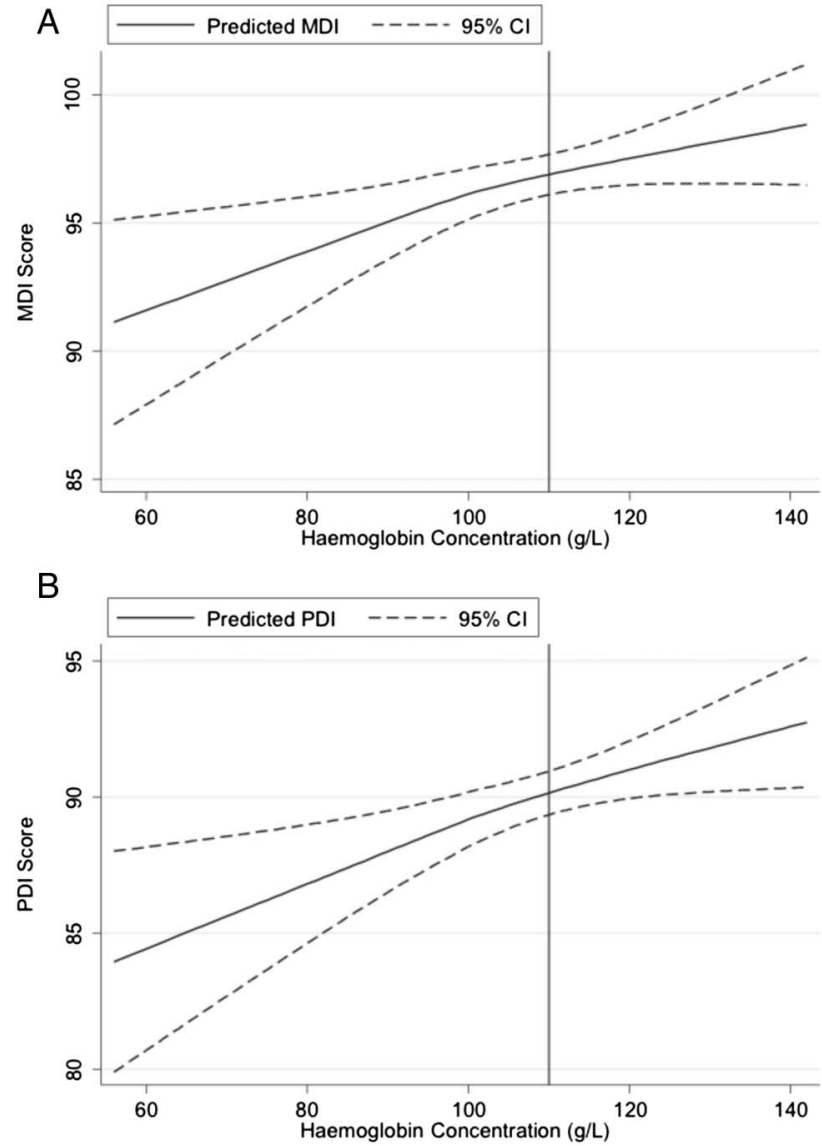

Figure 1 Panel A: Relationship between haemoglobin concentration and MDI score. Panel B: Relationship between haemoglobin concentration and PDI score. Lowess estimates of relationship between haemoglobin concentration and BSID score (BSID, Bayley Scales of Infant Development; MDI, Mental Development Index; PDI, Psychomotor Development Index).

Table 4 Association between Hb concentration and BSID scores $(n=1808)$

\begin{tabular}{|c|c|c|c|c|}
\hline & \multicolumn{2}{|l|}{ MDI score* } & \multicolumn{2}{|l|}{ PDI score } \\
\hline & Coefficient (95\% Cl) & p Value & Coefficient (95\% Cl) & p Value \\
\hline $\mathrm{Hb}$ concentration (g/L) & 0.09 (0.03 to 0.15$)$ & $<0.01$ & $0.10(0.04$ to 0.16$)$ & $<0.01$ \\
\hline Sex $($ female $=1)$ & $1.31(-0.16$ to 2.78$)$ & 0.08 & $0.44(-1.05$ to 1.93$)$ & 0.56 \\
\hline \multicolumn{5}{|l|}{ Infant age (6 months is base) (months) } \\
\hline 7 & 9.05 (5.56 to 12.53$)$ & $<0.01$ & 6.20 (3.30 to 9.10$)$ & $<0.01$ \\
\hline 8 & 7.79 (4.38 to 11.20$)$ & $<0.01$ & 4.06 (1.09 to 7.03$)$ & $<0.01$ \\
\hline 9 & 6.69 (3.17 to 10.21$)$ & $<0.01$ & $-0.65(-3.89$ to 2.58$)$ & 0.69 \\
\hline 10 & $5.92(2.34$ to 9.49$)$ & $<0.01$ & $-7.69(-11.0$ to -4.35$)$ & $<0.01$ \\
\hline 11 & $4.78(1.45$ to 8.12$)$ & $<0.01$ & $-2.04(-5.36$ to 1.28$)$ & 0.23 \\
\hline Is the infant premature? (yes=1) & $-1.70(-6.10$ to 2.69$)$ & 0.45 & $0.76(-2.71$ to 4.23$)$ & 0.67 \\
\hline Birth order of infant (second or higher $=1$ ) & $-0.83(-2.79$ to 1.14$)$ & 0.41 & $-1.37(-3.41$ to 0.67$)$ & 0.19 \\
\hline Mother is primary caregiver (yes $=1$ ) & $0.55(-1.49$ to 2.59$)$ & 0.60 & $1.40(-0.85$ to 3.65$)$ & 0.22 \\
\hline Maternal educational level (more than 9 years $=1$ ) & $0.96(-0.93$ to 2.85$)$ & 0.32 & $2.41(0.51$ to 4.30$)$ & 0.01 \\
\hline Maternal age (more than 25 years $=1$ ) & $-1.19(-3.12$ to 0.73$)$ & 0.22 & $-0.94(-2.86$ to 0.98$)$ & 0.34 \\
\hline $\begin{array}{l}\text { Family receives minimum living standard guarantee } \\
\text { (yes }=1 \text { ) }\end{array}$ & $-0.42(-2.16$ to 1.32$)$ & 0.64 & $-0.71(-2.58$ to 1.17$)$ & 0.46 \\
\hline
\end{tabular}


Our data further show that the high prevalence of anaemia that we observe is significantly correlated with high rates of cognitive and psychomotor delays, as measured by infant performance on the BSID. Around 20\% of the sample suffered from some degree of cognitive delay, while nearly one-third $(32.3 \%)$ of the sample suffered from some degree of psychomotor delay. These numbers are quite a bit higher than what would be expected in a normal population. In the urban Chinese population against which the BSID scores were normalised, only $11.7 \%$ of children would be expected to have cognitive delays, and only $11.0 \%$ would be expected to have psychomotor delays. In total, $39.2 \%$ of the sample suffered from one or both types of developmental delay, compared with an expected $22.7 \%$ in a healthy Chinese population. Moreover, children with lower $\mathrm{Hb}$ counts were significantly more likely to suffer from either type of delay.

The graph of the relationship between $\mathrm{Hb}$ concentrations and BSID scores demonstrates that the association between nutrition and child development exists both below and above the $110 \mathrm{~g} / \mathrm{L}$ mark, the traditional cut-off point used to identify an infant as having anaemia. In other words, even for those infants the $\mathrm{WHO}$ considers to be non-anaemic, higher $\mathrm{Hb}$ levels are associated with better cognitive and psychomotor development. While our data cannot prove causality, these results merit careful consideration, since they point to a link between $\mathrm{Hb}$ and child development even for children traditionally considered to be "healthy".

We note that our results are not sensitive to our treatment of infants failing to reach the minimum MDI score. As described in the Results section, in our sample, 31 infants, or $2 \%$ of the sample infants, failed to achieve the minimum score (50) on the MDI and were assigned a score of 49 . We included these measures in the analyses, reasoning that their inclusion helps contribute to better overall explanatory power. ${ }^{41}{ }^{42}$ Since some researchers prefer to exclude 'failing' observations from the analyses, ${ }^{43}{ }^{44}$ we also ran all of our analyses with these 31 failing observations excluded from the analysis $(n=1777$, not shown), and the results were not statistically different from the results shown in this paper.

The strengths of this study include its populationbased sampling technique, large sample size and rigorous child development testing, all of which increase confidence in the validity and generalisability of our findings. A primary weakness is that we were unable to conduct full blood panel testing for nutritional deficiencies, and are therefore limited to considering $\mathrm{Hb}$ as our sole indicator of micronutrient deficiency. We acknowledge that (1) low $\mathrm{Hb}$ levels alone do not definitively indicate iron deficiency and (2) other micronutrient deficiencies such as zinc, folate, or vitamin A may be driving our correlational results. While iron deficiency is not necessarily the only cause of anaemia in our sample areas, evidence suggests that other potential causes (such as helminthic infections) are unlikely to be the driving factor behind low levels of $\mathrm{Hb}$ among our sample population. ${ }^{45}$ Indeed, several studies report that $85-95 \%$ of anaemia in China is caused by iron deficiency. ${ }^{46}$

While our study highlights the important link between infant nutrition and early child development, we point out that other factors may also be at play. For example, studies elsewhere have indicated the importance of parental stimulation as a contributing factor to child development. ${ }^{47}$ Maternal mental health and the home environment may also play a role. ${ }^{48}{ }^{49}$ Since our study is correlational in nature, future work is needed to refine the results presented here and better identify whether a causal link exists between infant nutrition and early child development in rural China.

\section{Research in context}

Overall, our findings indicate that low $\mathrm{Hb}$ levels are a serious problem in poor areas of rural China, affecting a large proportion of Chinese infants living in these areas, and officially categorising anaemia as a 'severe' public health problem according to the WHO. ${ }^{50}$ The severity of this problem in a country that has already reached middle-income status is alarming, especially in the face of recent evidence that anaemia among this age group can be effectively treated with a low-cost daily iron supplement. ${ }^{51}$ Moreover, we find that the low $\mathrm{Hb}$ levels that we observe in this study are associated with significant cognitive and psychomotor delays that could eventually affect children's schooling performance and labour force outcomes. The Chinese government should take steps to ensure that these infants have access to a more balanced diet, and should do so before irreversible damage is done to this vulnerable population.

\section{Author affiliations}

${ }^{1}$ Chinese Academy of Sciences, Center for Chinese Agricultural Policy, Institute of Geographical Sciences and Natural Resources Research, Beijing, China

${ }^{2}$ Center for Experimental Economics in Education (CEEE), Shaanxi Normal University, Xi'an, Shaanxi, China

${ }^{3}$ West China School of Public Health, Sichuan University, Chengdu, Sichuan China

${ }^{4}$ School of Economics, Renmin University of China, Beijing, China

${ }^{5}$ Rural Education Action Program, Freeman Spogli Institute for International Studies, Stanford University, Stanford, California, USA

Acknowledgements The authors are grateful to the following for project funding: the International Initiative for Impact Evaluation (3ie), the UBS Optimus Foundation, China Medical Board, the Bank of East Asia, the HJ Heinz Company Foundation, the Huaqiao Foundation and Noblesse. They would also like to thank the dedicated leaders and local cadres at the National Health and Family Planning Commission for their unparalleled assistance in implementing this study.

Contributors RL, YS, HZ, SS, AM, LZ and SR conceived of and designed the study. RL, YS, HZ, AY and LZ collected the data used in the study. RL and SS analysed the data. RL, HZ, SS, AM and SR interpreted the results of the data analysis. AM drafted the manuscript. RL, YS, HZ, AY, SS, LZ and SR provided critical intellectual revisions. All the authors read and approved the final 
submitted version of the manuscript and accept accountability for all aspects of the work.

Funding International Initiative for Impact Evaluation (3ie) (grant number PW2.03.CH.IE), UBS Optimus Foundation (grant number 6140), China Medical Board (grant number 13-158), Bank of East Asia, HJ Heinz Company Foundation, Huaqiao Foundation and Noblesse.

Competing interests None declared.

Ethics approval This study received ethical approval from the Stanford University Institutional Review Board (IRB) (Protocol ID 25734) and from the Sichuan University Ethical Review Board (Protocol ID 2013005-01).

Provenance and peer review Not commissioned; externally peer reviewed.

Data sharing statement Statistical code and datasets are available from corresponding author on emailed request.

Open Access This is an Open Access article distributed in accordance with the Creative Commons Attribution Non Commercial (CC BY-NC 4.0) license, which permits others to distribute, remix, adapt, build upon this work noncommercially, and license their derivative works on different terms, provided the original work is properly cited and the use is non-commercial. See: http:// creativecommons.org/licenses/by-nc/4.0/

\section{REFERENCES}

1. Luo R, Wang X, Zhang $L$, et al. High anemia prevalence in western China. Southeast Asian J Trop Med Public Health 2011;42:1204-13.

2. News Office of the Ministry of Health. Report on the Nutritional Development of China's Children Aged 0-6 Years [in Chinese] Beijing: Ministry of Health of the People's Republic of China, 2012.

3. Grantham-McGregor S, Ani C. A review of studies on the effect of iron deficiency on cognitive development in children. J Nutr 2001;131:649S-66S

4. Akman M, Cebeci D, Okur V, et al. The effects of iron deficiency on infants' developmental test performance. Acta Paediatr 2004;93:1391-6.

5. Hasanbegovic E, Sabanovic S. Effects of iron therapy on motor and mental development of infants and small children suffering from iron deficiency anaemia. Med Arh 2004;58:227-9.

6. Idjradinata P, Pollitt E. Reversal of developmental delays in iron deficient anaemic infants treated with iron. Lancet 1993;341:1-4

7. Lozoff B, Brittenham GM, Wolf AW, et al. Iron deficiency anemia and iron therapy effects on infant developmental test performance. Pediatrics 1987;79:981-95.

8. Lozoff B, Wolf AW, Jimenez E. Iron-deficiency anemia and infant development: Effects of extended oral iron therapy. $J$ Pediatr 1996;129:382-9.

9. Walter T, de Andraca I, Chadud P, et al. Iron deficiency anemia: adverse effects on infant psychomotor development. Pediatrics 1989;84:7-17.

10. Lozoff B, Klein NK, Nelson EC, et al. Behavior of infants with iron-deficiency anemia. Child Dev 1998;69:24-36.

11. Sachdev H, Gera T, Nestel P. Effect of iron supplementation on mental and motor development in children: systematic review of randomised controlled trials. Public Health Nutr 2005;8:117-32.

12. Lozoff $\mathrm{B}$, Jimenez $\mathrm{E}$, Hagen J, et al. Poorer behavioral and developmental outcome more than 10 years after treatment for iron deficiency in infancy. Pediatrics 2000;105:e51.

13. Lozoff B, Jimenez E, Smith JB. Double burden of iron deficiency in infancy and low socioeconomic status: a longitudinal analysis of cognitive test scores to age 19 years. Arch Pediatr Adolesc Med 2006;160:1108-13.

14. Maluccio JA, Hoddinott J, Behrman JR, et al. The impact of improving nutrition during early childhood on education among Guatemalan adults. Econ J 2009;119:734-63.

15. Haas JD, Brownlie T IV. Iron deficiency and reduced work capacity: a critical review of the research to determine a causal relationship. J Nutr 2001;131:676S-88S; discussion 688S-690S.

16. Pasricha SR, Hayes E, Kalumba K, et al. Effect of daily iron supplementation on health in children aged 4-23 months: a systematic review and meta-analysis of randomised controlled trials. Lancet Glob Health 2013;1:e77-86.

17. Luo R, Shi Y, Zhang L, et al. Nutrition and educational performance in rural China's elementary schools: results of a randomized controlled trial in Shaanxi province. Econ Dev Cultur Change 2012;60:735-72.
18. Luo R, Shi $Y$, Zhang L, et al. The limits of health and nutrition education: evidence from three randomized controlled trials in rural China. CESifo Economic Studies 2012;58:385-404.

19. Kleiman-Weiner M, Luo R, Zhang L, et al. Eggs versus chewable vitamins: which intervention can increase nutrition and test scores in rural China? China Econ Rev 2013;24:165-76.

20. Lucas A. Programming by early nutrition: an experimental approach. J Nutr 1998;128:401S-6S

21. Grantham-McGregor S, Cheung YB, Cuento S, et al. Developmental potential in the first 5 years for children in developing countries. Lancet 2007;369:60-70.

22. Victora CG, Adair L, Fall C, et al. Maternal and child undernutrition: consequences for health and human capital. Lancet 2008;371: 340-57.

23. Zhang $\mathrm{X}$, Li H, Song $\mathrm{D}$, et al. Research on the anemia situation among poor, rural children in seven counties in Xinjiang [in Chinese]. Chin J Child Health Care 2009;006:621-3.

24. Dong $\mathrm{C}, \mathrm{Ge} \mathrm{P}$, Zhang $\mathrm{C}$, et al. Effects of different feeding practices at 0-6 months and living economic conditions on anemia prevalence of infants and young children [in Chinese]. Wei Sheng Yan Jiu 2013:42:596-9, 604.

25. Li Q, Yan H, Zeng L, et al. Effects of maternal micronutrient supplementation on the mental development of infants in rural western China: follow-up evaluation of a double-blind, randomized, controlled trial. Pediatrics 2009;123:e685.

26. de Onis M, Onyango AW, Van den Broeck J, et al. Measurement and standardization protocols for anthropometry used in the construction of a new international growth reference. Food Nutr Bull 2004;25:S27-36.

27. Bayley N. The Bayley scales of infant development: the mental scale. New York, NY: Psychological Corporation, 1974.

28. American Psychiatric Association. Diagnostic and statistical manual of mental disorders, fourth edition, text revision. Washington DC American Psychiatric Association, 2000.

29. Yi S, Luo X, Yang Z, et al. The revising of Bayley Scales of Infant Development (BSID) in China [in Chinese]. Chin J Clin Psychol 1993;1:71-5.

30. Huang H, Tao SD, Zhang YW, et al. Standardization of Bayley scales of infant development in Shanghai. Chin $J$ Child Health 1993;1:158-60.

31. Chang S, Zeng L, Brouwer ID, et al. Effect of iron deficiency anemia in pregnancy on child mental development in rural China. Pediatrics 2013;131:e755-63.

32. Wu W, Sheng D, Shao J, et al. Mental and motor development and psychosocial adjustment of Chinese children with phenylketonuria $J$ Paediatr Child Health 2011;47:441-7.

33. Yi S. Manual of Bayley scales of infant development, Chinese revision. Xiangya School of Medicine. Changsha, China: Central South University, 1995.

34. Bayley N. Bayley Scales of Infant Development. New York, NY: Psychological Corporation, 1969.

35. No authors listed]. Recommendations to prevent and control iron deficiency in the United States. Centers for Disease Control and Prevention. MMWR Recomm Rep 1998;47:1-29.

36. Life Sciences Research Office. Assessment of the iron nutrition status of the U.S. population based on data collected in the second national health and nutrition survey, 1976-1980. Bethesda, MD: Federation of American Societies for Experimental Biology, 1984.

37. WHO Multicentre Growth Reference Study Group. WHO child growth standards: length/height-for-age, weight-for-age, weight-for-length, weight-for-height and body mass index-for-age: methods and development. Geneva: World Health Organization, 2006.

38. de Onis M, Blossner M. WHO global database on child growth and malnutrition. Geneva: World Health Organization, 1997.

39. Moore T, Johnson S, Haider S, et al. Relationship between test scores using the second and third editions of the Bayley Scales in extremely preterm children. J Pediatr 2012;160:553-8.

40. Stevens GA, Finucane MM, De-Regil LM, et al. Global, regional, and national trends in haemoglobin concentration and prevalence of total and severe anaemia in children and pregnant and non-pregnant women for 1995-2011: a systematic analysis of population-representative data. Lancet Global Health 2013;1: e16-25.

41. Hack M, Taylor HG, Drotar D, et al. Poor predictive validity of the Bayley scales of infant development for cognitive function of extremely low birth weight children at school age. Pediatrics 2005;116:333-41.

42. Gay CL, Armstrong FD, Cohen D, et al. The effects of HIV on cognitive and motor development in children born to HIV-seropositive women with no reported drug use: birth to 24 months. Pediatrics 1995;96:1078-82. 
43. McCathren RB, Yoder PJ, Warren SF. Testing predictive validity of the communication composite of the communication and symbolic behavior scales. J Early Interv 2000;23:36-46.

44. Hamadani JD, Fuchs GJ, Osendarp SJM, et al. Randomized controlled trial of the effect of zinc supplementation on the mental development of Bangladeshi infants. Am J Clin Nutr 2001;74:381-6.

45. Wang $X$, Zhang $L$, Luo $R$, et al. Soil-transmitted helminth infections and correlated risk factors in preschool and school-aged children in rural southwest China. PLoS ONE 2012;7:e45939.

46. Du S, Zhai F, Wang $\mathrm{Y}$, et al. Current methods for estimating dietary iron bioavailability do not work in China. J Nutr 2000;130:193-8.

47. Attanasio OP, Fernández $\mathrm{C}$, FitzsimonsEmla $\mathrm{OA}$, et al. Using the infrastructure of a conditional cash transfer program to deliver a scalable integrated early child development program in Colombia: cluster randomized controlled trial. BMJ 2014;349:g5785.
48. Patel V, Rahman A, Jacob KS, et al. Effect of maternal health on infant growth in low income countries: new evidence from South Asia. BMJ 2004;328:820-3.

49. Rodriguez ET, Tamis-LeMonda CS. Trajectories of the home learning environment across the first 5 years: associations with children's vocabulary and literacy skills at prekindergarten. Child Dev 2011;82:1058-75.

50. World Health Organization. Iron deficiency anaemia: assessment, prevention, and control. A guide for programme managers. Geneva: World Health Organization, 2001.

51. Pasricha SR, Hayes E, Kalumba K, et al. Effect of daily iron supplementation on health in children aged 4-23 months: a systematic review and meta-analysis of randomised controlled trials. Lancet Global Health 2013;1:e77-86. 